\title{
Mathematical Model With Phosphate Activation Effect Validates Batch (R)-phenylacetylcarbinol Biotransformation Process Utilizing Candida Tropicalis Pyruvate Decarboxylase in Phosphate Buffer
}

Julaluk Khemacheewakul

Chiang Mai University

Siraphat Taesuwan

Chiang Mai University

Rojarej Nunta

Chiang Mai University

Charin Techapun

Chiang Mai University

Yuthana Phimolsiripol

Chiang Mai University

Pornchai Rachtanapun

Chiang Mai University

Kittisak Jantanasakulwong

Chiang Mai University

Kritsadaporn Porninta

Chiang Mai University

Sumeth Sommanee

Chiang Mai University

Chatchadaporn Mahakuntha

Chiang Mai University

Thanongsak Chaiyaso

Chiang Mai University

Phisit Seesuriyachan

Chiang Mai University

Alissara Reungsang

Khon Kaen University

Ngoc Thao Ngan Trinh

Nong Lam University - Ho Chi Minh City 


\section{Sutee Wangtueai}

Chiang Mai University

\section{Sarana Rose Sommano}

Chiang Mai University

Noppol Leksawasdi ( $\nabla$ noppol@hotmail.com )

Chiang Mai University

\section{Research Article}

Keywords: Candida tropicalis, phenylacetylcarbinol, pyruvate decarboxylase, mathematical model, biotransformation, phosphate buffer

Posted Date: April 14th, 2021

DOl: https://doi.org/10.21203/rs.3.rs-404727/v1

License: (c) (i) This work is licensed under a Creative Commons Attribution 4.0 International License. Read Full License 


\title{
Mathematical model with phosphate activation effect validates batch $(R)$-phenylacetylcarbinol biotransformation process utilizing Candida tropicalis pyruvate decarboxylase in phosphate buffer
}

\author{
Julaluk Khemacheewakul ${ }^{1,2}$, Siraphat Taesuwan ${ }^{1,2}$, Rojarej Nunta ${ }^{1,3}$, \\ Charin Techapun $^{1,2}$, Yuthana Phimolsiripol ${ }^{1,2,4}$, Pornchai Rachtanapun ${ }^{1,2,4}$, \\ Kittisak Jantanasakulwong ${ }^{1,2,4}$, Kritsadaporn Porninta ${ }^{1,2}$, Sumeth Sommanee ${ }^{1,2}$, \\ Chatchadaporn Mahakuntha $^{1,2}$, Thanongsak Chaiyaso ${ }^{1,2}$, Phisit Seesuriyachan ${ }^{1,2}$, \\ Alissara Reungsang ${ }^{5,6,7}$, Ngoc Thao Ngan Trinh ${ }^{8}$, Sutee Wangtueai', Sarana Rose \\ Sommano $^{10}$ \& Noppol Leksawasdi ${ }^{1,2,4 *}$
}

${ }^{1}$ Cluster of Agro Bio-Circular-Green Industry (Agro BCG), School of Agro-Industry, Faculty of Agro-Industry, Chiang Mai University, Chiang Mai, 50100, Thailand

${ }^{2}$ Faculty of Agro-Industry, Chiang Mai University, Chiang Mai, 50100, Thailand

${ }^{3}$ Division of Food Innovation and Business, Faculty of Agricultural Technology, Lampang Rajabhat University, Lampang, 52100, Thailand

${ }^{4}$ Center of Excellence in Materials Science and Technology, Faculty of Science, Chiang Mai University, Chiang Mai, 50100, Thailand

${ }^{5}$ Research Group for Development of Microbial Hydrogen Production Process, Khon Kaen University, Khon Kaen, 40002, Thailand

${ }^{6}$ Department of Biotechnology, Faculty of Technology, Khon Kaen University, Khon Kaen, 40002, Thailand

${ }^{7}$ Academy of Science, Royal Society of Thailand, Bangkok, 10300, Thailand

${ }^{8}$ Department of Food Engineering, Faculty of Food Science and Technology, Nong Lam University Ho Chi Minh City, Linh Trung Ward, Thu Duc District, Ho Chi Minh City, 720371, Vietnam

${ }^{9}$ College of Maritime Studies and Management, Chiang Mai University, Samut Sakhon, 74000, Thailand

${ }^{10}$ Plant Bioactive Compound Laboratory, Faculty of Agriculture, Chiang Mai University, Chiang Mai 50200, Thailand

*Corresponding author noppol@ hotmail.com, Mobile: +66-81-950-6544

Novelty: The existing $(R)$ - phenylacetylcarbinol (PAC) biotransformation model in literatures did not include activation effect of buffering species into the enzyme deactivating rate equation, thereby background deactivation and buffering activation effects could not be discerned. A new mathematical model which incorporated activation effect, using $250 \mathrm{mM}$ phosphate buffer as an example, was able to predict and validate PAC batch biotransformation systems reasonably well and could pave the way for model applications in more complex processes. 


\section{ABSTRACT}

The new $(R)$ - phenylacetylcarbinol (PAC) batch biotransformation kinetics for partially purified Candida tropicalis TISTR 5350 pyruvate decarboxylase (PDC) were characterized and validated with a comprehensive mathematical model in $250 \mathrm{~mL}$ scale with $250 \mathrm{mM}$ phosphate buffer / pH 7.0. PDC could convert initial 100 / $120 \mathrm{mM}$ benzaldehyde / pyruvate substrates to the statistical significantly highest $(p \leq 0.05)$ maximum PAC concentration $(95.8$ $\pm 0.1 \mathrm{mM})$ and production rate $\left(0.639 \pm 0.001 \mathrm{mM} \mathrm{min}^{-1}\right)$. A parameter search strategy aimed at minimizing overall residual sum of square $\left(\mathrm{RSS}_{T}\right)$ based on a system of six ordinary differential equations was applied to PAC biotransformation profiles with initial benzaldehyde / pyruvate concentration of 100/120 and 30/36 mM. Ten important biotransformation kinetic parameters were then elucidated including the zeroth order activation rate constant due to phosphate buffer species $\left(k_{a}\right)$ of $(9.38 \pm<0.01) \times 10^{-6} \%$ relative PDC activity $\mathrm{min}^{-1} \mathrm{mM}^{-1}$. The validation of this model to independent biotransformation kinetics with initial benzaldehyde / pyruvate concentration of 50 / $60 \mathrm{mM}$ resulted in relatively good fitting with $\mathrm{RSS}_{T}$, mean sum of square error (MSE), and coefficient of determination $\left(\mathrm{R}^{2}\right)$ values of $662,17.4$, and 0.9863 , respectively.

Keywords: Candida tropicalis; phenylacetylcarbinol; pyruvate decarboxylase; mathematical model; biotransformation; phosphate buffer

\section{Introduction}

Microbial biotransformation has been extensively used worldwide in the pharmaceutical industry followed by the food and agriculture sectors ${ }^{1,2}$ for almost 20 years. Revenue generated by microbial biotransformation steadily increased from USD 0.39 trillion in 2001 to USD 1.25 trillion in 2019 within the pharmaceutical industry. The food and agriculture sectors had estimated USD 1.13 trillion (2019) and USD 1.84 billion (2018) in revenue respectively from microbial biotransformation ${ }^{3-5}$. Although chemocatalysts can offer the relatively high catalytic activity and selectivity for some reactions ${ }^{6,7}$, a number of organic compounds transformation processes still rely heavily on biocatalysts to achieve the desired level of enantioselectivity ${ }^{8-10}$. Thus, biocatalysts including enzymes, cells organelles, and whole cells in either native or artificially constructed forms ${ }^{11}$ have been widely used in the production of both high-volume / low-value compounds such as ethanol ${ }^{12-17}$ and low-volume / high-value chemical species including $(R)$-phenylacetylcarbinol (PAC) $)^{2,15,18-24}$.

The biochemical production of PAC was firstly demonstrated in Germany and later commercialized for ephedrine production ${ }^{25-27}$. PAC could be produced through in vivo direct microbial transformation process with some strategies of benzaldehyde feeding using growing cells of yeasts, fungi, and bacteria ${ }^{28-30}$. This biotransformation process can be conducted in vitro by using non-viable whole cells ${ }^{15,17,24}$ and partially purified pyruvate decarboxylase (PDC) enzyme ${ }^{18,20,28,29,31-34}$. The detailed reaction mechanism of PAC biotransformation was clearly elucidated ${ }^{18}$. Advantages of using partially purified PDC include prevention of benzyl alcohol or PAC-diol, by-products that are often formed when PAC biotransformation is performed in parallel with microbial cultivation process ${ }^{32,35}$. Moreover, the isolated enzymes could be recycled and reused during a biotransformation process ${ }^{27}$. The partially purified 
Candida utilis (ICI Australia) could produce $190.4 \mathrm{mM}$ PAC with molar yield as high as $95.3 \%$ based on benzaldehyde ${ }^{31,32,35}$. The PAC concentration could generally be increased through fed-batch processes with either pyruvate (in the form of pyruvic acid) or benzaldehyde dosing protocols using $2.5 \mathrm{M}$ or $20 \mathrm{mM}$ of 3-morpholinopropane-1-sulfonic acid (MOPS) buffer ${ }^{18-}$ 20,33. However, the heat labile property and cost-prohibitive nature of MOPS buffer (USD $1.09 / \mathrm{g}$ in comparison with only USD $0.02 / \mathrm{g}$ for phosphate buffer) were considered major obstacles to the industrial scale application of this buffering compound ${ }^{34}$.

Our previous research showed that, among fifty microbial strains, C. tropicalis TISTR 5350 and 5306 were the best yeast strains for PAC production. The two strains yielded $70 \%$ increase in volumetric PDC carboligase activity $\left(0.39 \pm 0.06 \mathrm{U} \mathrm{mL}^{-1}\right)$ and $58 \%$ increased PAC production $(19.8 \pm 3.4 \mathrm{mM})^{21}$. However, the strain TISTR 5306 was most suitable for longan extract medium ${ }^{16,21-23,34}$. Cells disruption strategy with $15 \mu \mathrm{g} \mathrm{mL}^{-1}$ silver nanoparticles was effective in reducing the treatment time to 3 min prior to purification steps of the released PDC from whole cells of $C$. tropicalis TISTR $5350^{23}$. The subsequent investigation on the best strategy to obtain partially purified PDC revealed that the specific PDC activity obtained from $50 \%(\mathrm{v} / \mathrm{v})$ acetone precipitation was statistically higher than $40-60 \%(\mathrm{w} / \mathrm{v})$ ammonium sulphate counterparts ${ }^{23}$. In order to minimize cost, prevent relatively high overall losses of enzyme activity through purification process, and avoid utilization of cost ineffective MOPS buffer, Khemacheewakul et al. ${ }^{34}$ used whole cells $C$. tropicalis TISTR 5350 in single phase PAC production and benzaldehyde deactivation studies with various concentrations of phosphate buffer $(20 \mathrm{mM}-2.5 \mathrm{M})$. A thorough examination indicated that $1 \mathrm{M}$ phosphate buffer was optimal for PAC production $(28.6 \pm 2.3 \mathrm{mM})$ and provided additional activation effect to PDC stability. The average PDC activation rate constant of $1 \mathrm{M}$ phosphate buffer was higher than $20 \mathrm{mM}$ by more than 9,050 times. Leksawasdi et al. ${ }^{2}$ projected that in a circulated system of recycled phosphate buffer and related co-factors utilizing whole cells of Saccharomyces cerevisiae and C. tropicalis co-culture as biocatalysts, the costing of phosphate buffer would be USD 0.751 per $1 \mathrm{~kg}$ of produced PAC. The similar investigation on the partially purified PDC of $C$. tropicalis TISTR 5350 is thus required to evaluate relevant PAC production characteristics and assess whether the newly developed deactivation rate equation can interact well to the other five rate equations in a PAC biotransformation mathematical model.

The objectives of present study are to investigate the effects of initial substrates concentration pairs (benzaldehyde/pyruvate of 30/36, 50/60, and 100/120 mM) and phosphate buffer concentration levels $(20,250,500$, and $1 \mathrm{M} ; \mathrm{pH} 7.0)$ on PAC production, PAC formation rate, and PAC molar yields using partially purified $C$. tropicalis TISTR 5350 in the $250-\mathrm{mL}$ single phase batch biotransformation system. In addition, the recently improved mathematical model comprised six ordinary differential equations plus PDC-activation effect by phosphate buffering species is used to determine ten kinetic parameters based on biotransformation profiles of the $30 / 36$ and $100 / 120 \mathrm{mM}$ initial benzaldehyde / pyruvate concentration pairs. The model is then validated with an independent batch biotransformation system using initial substrates concentration pair of $50 / 60 \mathrm{mM}$ followed by assessment of relevant statistical parameters. 


\section{Materials and methods}

Microorganism. C. tropicalis TISTR 5350 was purchased from Thailand Institute of Scientific and Technological Research (TISTR, Pathum Thani, Thailand) before subculturing into primary stock ${ }^{21}$. The microbial stock was kept in $60 \%(\mathrm{v} / \mathrm{v})$ glycerol solution and maintained at $-70^{\circ} \mathrm{C}$ with regular assessments of cells viability by using a haemocytometer ${ }^{16}$. The viable cells count was $92.5 \pm 1.8 \%{ }^{21}$. C. tropicalis TISTR 5350 was chosen based on optimal PAC production and volumetric PDC carboligase activity in Yeast - Malt (YM) medium ${ }^{16,21-23,34}$.

Cultivation of microbes and production of partially purified PDC. The cultivation of preseed and seed was done in 0.1 and $1 \mathrm{~L}$ yeast media as described by Khemacheewakul et al. ${ }^{34}$. In order to produce enough wet biomass for the production of partially purified PDC, the cultivation was carried out at $30^{\circ} \mathrm{C}$ for $36 \mathrm{~h}$ in a 161 stainless steel bioreactor containing 101 inoculum medium with a composition similar to those published previously by our group ${ }^{23}$. The methodologies for preparation of cells pellet, glass bead pretreatment, subsequent precipitation with $50 \%(\mathrm{v} / \mathrm{v})$ acetone, and production of partially purified PDC have already been stated elsewhere ${ }^{22,23}$.

PDC production in phosphate buffer with various buffer and initial substrate concentration levels. The $\mathrm{pH}$-controlled, single-phase batch biotransformation system was carried out for 210-min with a sampling interval of $30 \mathrm{~min}$ at $4^{\circ} \mathrm{C}$ in $250 \mathrm{~mL}$ phosphate buffer $(\mathrm{pH} 7.0)^{34}$. This buffer is also known as the Gomori buffer because it contains the $\mathrm{K}_{2} \mathrm{HPO}_{4}$ and $\mathrm{KH}_{2} \mathrm{PO}_{4}$ conjugated acid-base pair ${ }^{36}$. A full factorial design experiment with four phosphate buffer concentration levels $(20,250,500$, and $1 \mathrm{M})$ and three pairs of initial benzaldehyde/pyruvate substrate concentration levels (30/36, 50/60 and 100/120) were conducted. A total of $4 \times 3=12$ groups was studied in quintuplicates. The rationale for selecting phosphate buffer at these four concentration levels utilized also by previous studies had already been elaborated in details elsewhere ${ }^{34}$. Partially purified PDC was added as a biocatalyst while $1 \mathrm{mM}$ thiamine pyrophosphate (TPP) and $1 \mathrm{mM} \mathrm{MgSO}_{4} .7 \mathrm{H}_{2} \mathrm{O}$ were also included as cofactors $^{29,35}$. Maximum PAC production level $(\mathrm{mM})$, maximum PAC formation rate $(\mathrm{mM}$ $\min ^{-1}$ ), and corresponding PAC molar yield (the ratio of PAC being produced over substrate being consumed) for each substrate pair at the maximum PAC production level were measured using high performance liquid chromatography (HPLC). The maximum PAC formation rate was computed by dividing maximum PAC production level at each time point with its corresponding reaction time $(30,60,90,120,150,180$, and $210 \mathrm{~min})$. The initial volumetric PDC carboligase activity in each experiment was maintained between $1.1-1.5 \mathrm{U}$ carboligase $\mathrm{mL}^{-1}$.

Analytical Methods. The collected samples were separated into liquid buffering and enzymatic portions through centrifugation process prior to respective sample pretreatment stages as described in literatures ${ }^{19,20,29,32,33,35}$. PAC, benzaldehyde, benzyl alcohol, and benzoic acid concentration levels were determined by using HPLC as previously described by Rosche et al. ${ }^{29}$. Acetoin was analyzed by HPLC equipped with the HPX-87 H column ${ }^{37}$. Pyruvate concentration was determined spectrophotometrically by using the enzymatic $\mathrm{NADH}+\mathrm{H}^{+}$ coupled assay method with lactate dehydrogenase based on the modified method from Czok and Lamprecht ${ }^{38}$. Acetaldehyde concentration was determined in the same manner as the 
pyruvate assay with the replacement of lactate dehydrogenase with alcohol dehydrogenase based on a modified method from Bernt and Bergmeyer ${ }^{39}$. One unit PDC carboligase activity was defined as the rate of which $1 \mu$ mol PAC was produced from equimolar benzaldehyde and pyruvate per min in carboligase buffer at $\mathrm{pH} 6.0$ and $25^{\circ} \mathrm{C}^{18}$.

Hypothesis testing. Averages and standard errors were calculated from experimental data in quintuplicates. The results obtained were statistically analyzed using SPSS for Windows 22.0 (SPSS Inc., Chicago, IL, USA) and the analysis of variance using Duncan's Multiple Range Test (DMRT) at $p \leq 0.05^{15,24,40}$.

Construction of PAC biotransformation model. The PAC biotransformation model for $C$. tropicalis TISTR 5350 in this study consisted of six rate equations that described the main product (PAC) formation (1), substrates (pyruvate and benzaldehyde) consumption (2, 3), byproducts (acetaldehyde and acetoin) formation $(4,5)$ as well as deactivation of pyruvate decarboxylase with inorganic phosphate activation effect (6). Eq. (1) to (5) were derived and determined based on the combined King and Altman schematic strategy as well as the initial rate studies by Leksawasdi et al. ${ }^{18-20}$. Eq. (6) was modified and developed by Khemacheewakul et al. ${ }^{34}$ for whole cells $C$. tropicalis TISTR 5350. This equation combined both the PDC deactivation effect by background species excluding buffer concentration and benzaldehyde $\left(k_{d 1}, k_{d 2}\right)$ as well as the PDC activation effect by inorganic phosphate species $\left(\mathrm{K}_{2} \mathrm{HPO}_{4} / \mathrm{KH}_{2} \mathrm{PO}_{4}\right)$ within the $20 \mathrm{mM}$ to $1 \mathrm{M}$ concentration range $\left(k_{a}\right)$. The complete simulation profile for each species of PAC biotransformation kinetics was constructed based on EulerCauchy numerical integration with a time increment of $0.01 \mathrm{~h}^{18}$. The description for each parameter / variable is given in the nomenclature section.

$$
\begin{aligned}
& \left.\frac{d P}{d t}\right|_{i}=V_{p}\left(\frac{K_{b} B_{i}^{h}}{1+K_{b} B_{i}^{h}}\right)\left(\frac{A_{i}}{K_{m a}+A_{i}}\right) E_{i} \\
& \left.\frac{d A}{d t}\right|_{i}=-\left.\frac{d P}{d t}\right|_{i}-\left.\frac{d Q}{d t}\right|_{i}-\left.2 \frac{d R}{d t}\right|_{i} \\
& \left.\frac{d B}{d t}\right|_{i}=-\left.\frac{d P}{d t}\right|_{i} \\
& \left.\frac{d Q}{d t}\right|_{i}=V_{q} A_{i} E_{i}-V_{r} A_{i} Q_{i} E_{i} \\
& \left.\frac{d R}{d t}\right|_{i}=V_{r} A_{i} Q_{i} E_{i} \\
& \left.\frac{d E}{d t}\right|_{i}=\left\{\begin{aligned}
0, & t<t_{\text {lag }} \\
-\left(k_{d 1}+k_{d 2} \cdot B\right) E_{i}+k_{a} . P, & t \geq t_{\text {lag }}
\end{aligned}\right.
\end{aligned}
$$


Strategy for parameters estimation and model validation. The initial values of each parameter for Eq. (1) - (5) were averaged from values reported in previous initial rate and simulation studies of a high-buffering-capacity biotransformation system ${ }^{18,19}$ using partially purified PDC from $C$. utilis in 2.5 M MOPS buffer (Table 2). The initial values for the zeroth order activation rate constant due to phosphate buffer species $\left(k_{a}\right)$ as well as the other three parameters $\left(k_{d 1}, k_{d 2}\right.$ and $\left.t_{\text {lag }}\right)$ in Eq. (6) were obtained from a recent PDC deactivation study using whole cells PDC from $C$. tropicalis TISTR $5350^{34}$ in $20 \mathrm{mM}-1 \mathrm{M}$ phosphate buffer. Parameter estimation and model validation were performed using the customized and well established subroutines written in Microsoft Visual Basic for Applications (VBA) 6.3 for Microsoft EXCEL ${ }^{\circledR 12,14,18,19,34}$. Specifically, the minimization of total residual sum of square $\left(\mathrm{RSS}_{T}\right)$ between experimental data and simulated values from the model, and the convergence search criterion (CSC) of lesser than $1 \%$ of $\mathrm{RSS}_{T}$ were set as objective functions while the mean square error (MSE) and the coefficient of determination $\left(\mathrm{R}^{2}\right)$ were calculated simultaneously. $\mathrm{RSS}_{T}$ for each set of biotransformation profiles is the summation of individual RSS values for product and by-products formation, substrates consumption, and enzyme deactivation profiles as shown in Eq. (7). MSE is the ratio of $\mathrm{RSS}_{T}$ and available degree of freedom (DOF) for each system. DOF is the number of experimental data points being regressed minus the total number of parameters in the mathematical model. Biotransformation profile data from the $30 / 36$ and the 100 / $120 \mathrm{mM}$ initial benzaldehyde / pyruvate concentration pairs were used for parameter estimation in this biotransformation model. The error estimation of each parameter was evaluated using the standard error of each time point as described by Khemacheewakul et al. ${ }^{34}$.

$$
\mathrm{RSS}_{T}=\mathrm{RSS}_{A}+\mathrm{RSS}_{B}+\mathrm{RSS}_{Q}+\mathrm{RSS}_{R}+\mathrm{RSS}_{E}
$$

Where $A$ refers to pyruvate concentration, $B$ refers to benzaldehyde concentration, $Q$ refers to acetaldehyde concentration, $R$ refers to acetoin concentration, and $E$ refers to relative enzyme activity.

The estimated parameters were then validated by being implemented in Eq. (1) - (6) and numerically integrated to simulate the biotransformation profiles of an independent data set obtained from the 50/60 mM substrate pair. The assessment of relevant statistical parameters $\left(\mathrm{RSS}_{T}, \mathrm{MSE}, \mathrm{R}^{2}\right)$ was then made to evaluate the quality of fit. 


\section{Results}

PDC production in phosphate buffer with various buffer and initial substrate concentration levels. The current study investigated a single-phase batch biotransformation process using partially purified $C$. tropicalis TISTR 5350 PDC as a biocatalyst. The maximum PAC production levels $\left(P_{\max }\right)$, maximum PAC formation rates $\left(\mathrm{r}_{P_{\max }}\right)$, and PAC molar yields with respect to each substrate $\left(\mathrm{Y}_{P / B}\right.$ and $\left.\mathrm{Y}_{P / A}\right)$ under different initial substrate and phosphate buffer concentration levels are tabulated in Table 1. The $100 / 120 \mathrm{mM}$ initial benzaldehyde / pyruvate substrate pair in $250 \mathrm{mM}$ phosphate buffer showed the highest statistical significantly highest $(p \leq 0.05) P_{\max }(95.8 \pm 0.1 \mathrm{mM})$ and $\mathrm{r}_{P \max }\left(0.639 \pm 0.001 \mathrm{mM} \mathrm{min}^{-1}\right)$ with corresponding $\mathrm{Y}_{P / \mathrm{B}}$ and $\mathrm{Y}_{P / \mathrm{A}}$ of $0.99 \pm 0.01$ and $0.88 \pm 0.01$ based on benzaldehyde and pyruvate, respectively.

Table 1: Concentration level effects of phosphate buffer $\left(P h_{b}\right)$ and initial substrates (benzaldehyde $(B)$ as well as pyruvate $(A))$ on maximum PAC production levels $\left(P_{\max }\right)$, maximum PAC formation rates $\left(\mathrm{r}_{P \max }\right)$, as well as corresponding PAC - substrate molar yields based on benzaldehyde $\left(\mathrm{Y}_{P / B}\right)$ and pyruvate $\left(\mathrm{Y}_{P / A}\right)$ being consumed at maximum PAC production level in single - phase biotransformation systems with initial volumetric enzyme activity between $1.1-1.5 \mathrm{U}$ carboligase $\mathrm{mL}^{-1}$.

\begin{tabular}{|c|c|c|c|c|c|c|c|c|c|c|c|c|c|c|c|c|c|}
\hline \multirow{3}{*}{$\begin{array}{l}(B / A) \\
(\mathbf{m M})\end{array}$} & \multirow{3}{*}{$\begin{array}{c}\begin{array}{c}P h_{b} \\
(\mathbf{m M})\end{array} \\
20\end{array}$} & \multirow{2}{*}{\multicolumn{4}{|c|}{$\begin{array}{c}P_{\max } \\
(\mathbf{m M})\end{array}$}} & \multirow{2}{*}{\multicolumn{4}{|c|}{$\mathbf{r}_{P \max }\left(\mathbf{m M} \min ^{-1}\right)$}} & \multicolumn{8}{|c|}{$Y_{P_{\max }}$ for each substrate } \\
\hline & & & & & & & & & & \multicolumn{4}{|c|}{$\mathbf{Y}_{P_{\max / B}}$} & \multicolumn{3}{|c|}{$\mathbf{Y}_{P_{\max / A}}$} & \\
\hline & & 15.3 & \pm & 0.26 & $\mathrm{f}$ & 0.128 & \pm & 0.001 & $\mathrm{f}$ & 0.87 & \pm & 0.01 & $\mathrm{c}$ & 0.62 & \pm & 0.01 & $\mathrm{~g}$ \\
\hline \multirow{4}{*}{$\begin{array}{l}(30 / \\
36)\end{array}$} & 250 & 25.8 & \pm & 0.14 & $\mathrm{e}$ & 0.143 & \pm & 0.001 & $\mathrm{f}$ & $\underline{0.97}$ & \pm & $\underline{0.01}$ & $\underline{\mathbf{a b}}$ & $\underline{0.97}$ & \pm & $\underline{0.04}$ & $\underline{\mathbf{a b}}$ \\
\hline & 500 & 25.4 & \pm & 0.28 & $\mathrm{e}$ & 0.169 & \pm & 0.001 & ef & 0.95 & \pm & 0.01 & $\mathrm{~b}$ & 0.66 & \pm & 0.01 & $\mathrm{f}$ \\
\hline & 1,000 & 15.5 & \pm & 0.09 & $\mathrm{f}$ & 0.103 & \pm & 0.001 & $\mathrm{~g}$ & $\underline{0.97}$ & \pm & $\underline{0.01}$ & $\underline{\mathbf{a b}}$ & 0.81 & \pm & 0.01 & $\mathrm{e}$ \\
\hline & 20 & 40.6 & \pm & 0.21 & $\mathrm{c}$ & 0.193 & \pm & 0.001 & $\mathrm{e}$ & $\underline{0.99}$ & \pm & $\underline{0.01}$ & $\underline{\mathbf{a}}$ & $\underline{0.99}$ & \pm & $\underline{0.01}$ & $\underline{\mathbf{a}}$ \\
\hline \multirow{4}{*}{$\begin{array}{l}(50 / \\
60)\end{array}$} & 250 & 39.2 & \pm & 0.62 & $\mathrm{c}$ & 0.261 & \pm & 0.001 & $\mathrm{~d}$ & $\underline{0.99}$ & \pm & $\underline{0.04}$ & $\underline{\mathbf{a}}$ & 0.93 & \pm & 0.01 & $\mathrm{c}$ \\
\hline & 500 & 39.5 & \pm & 1.14 & $\mathrm{c}$ & 0.188 & \pm & 0.005 & $\mathrm{e}$ & $\underline{0.96}$ & \pm & $\underline{0.03}$ & $\underline{\mathbf{a b}}$ & $\underline{0.99}$ & \pm & $\underline{\mathbf{0 . 0 3}}$ & $\underline{\mathbf{a}}$ \\
\hline & 1,000 & 35.2 & \pm & 0.13 & $\mathrm{~cd}$ & 0.168 & \pm & 0.001 & ef & $\underline{0.98}$ & \pm & $\underline{0.00}$ & $\underline{\mathbf{a b}}$ & 0.90 & \pm & 0.02 & $\mathrm{~d}$ \\
\hline & 20 & 83.7 & \pm & 0.46 & $\mathrm{~b}$ & 0.465 & \pm & 0.001 & $\mathrm{c}$ & $\underline{0.98}$ & \pm & $\underline{0.01}$ & $\underline{\mathbf{a b}}$ & 0.95 & \pm & 0.01 & $b c$ \\
\hline \multirow{3}{*}{$\begin{array}{c}(100 / \\
120)\end{array}$} & 250 & $\underline{95.8}$ & \pm & $\underline{0.11}$ & $\underline{\mathbf{a}}$ & $\underline{0.639}$ & \pm & $\underline{0.001}$ & $\underline{\mathbf{a}}$ & $\underline{0.99}$ & \pm & $\underline{0.01}$ & $\underline{\mathbf{a}}$ & 0.88 & \pm & 0.01 & $\mathrm{~d}$ \\
\hline & 500 & 85.5 & \pm & 0.65 & $\mathrm{~b}$ & 0.407 & \pm & 0.001 & $\mathrm{c}$ & $\underline{0.99}$ & \pm & $\underline{0.01}$ & $\underline{\mathbf{a}}$ & $\underline{0.99}$ & \pm & $\underline{0.01}$ & $\underline{\mathbf{a}}$ \\
\hline & 1,000 & 89.7 & \pm & 0.62 & $\mathrm{~b}$ & 0.598 & \pm & 0.001 & $\mathrm{~b}$ & $\underline{0.99}$ & \pm & $\underline{0.01}$ & $\underline{\mathbf{a}}$ & $\underline{0.98}$ & \pm & $\underline{0.01}$ & $\underline{\mathbf{a b}}$ \\
\hline
\end{tabular}

The numbers with the same alphabet $(\mathrm{a}-\mathrm{g})$ indicated no statistical significantly difference $(p>0.05)$ for comparison between different rows of the same column within each group of initial substrates concentration pair. Bold and underline numbers and alphabets showed the statistical highest values within each column.

The reaction time resulting in the $P_{\max }$ for each run could be determined by dividing $P_{\max }$ with $\mathrm{r}_{\max }$ whose value was the multiple of $30 \mathrm{~min}(30,60,90,120,150,180$, and $210 \mathrm{~min})$. Rounding-off errors of the tabulated values might result in noninteger reaction times which should be rounded to the nearest multiple of $30 \mathrm{~min}$, for instance, reaction time for PAC biotransformation with initial substrates $(B, A)$ of $(30,36) \mathrm{mM}$ in $250 \mathrm{mM}$ phosphate buffer producing $P_{\max }$ of $25.8 \mathrm{mM}$ was $25.8 \mathrm{mM} / 0.143 \mathrm{mM} \mathrm{min} \operatorname{mon}^{-1}=180.42 \approx 180 \mathrm{~min}$. 
PAC biotransformation model and model validation. Simultaneous numerical integration of rate equations Eq. (1) - (6) was implemented to simulate a combined biotransformation kinetic profile of two benzaldehyde/pyruvate concentration pairs: $30 / 36$ and 100/120 mM. The simulation profiles of the optimized parameters are shown in Fig. 1(a) and 1(b). The initial searching values were extracted from Leksawasdi et al. ${ }^{18,19}$ and Khemacheewakul et al. ${ }^{34}$ (Table 2). Optimization of these kinetic values by a grid-search parameter estimation strategy improved fitting of the model as evident by lowering of $\operatorname{RSS}_{T}$ from 67,465 to 3,462 and MSE from 1,775 to 91.1 (19.5 times improvement). Model fitting statistics $\mathrm{RSS}_{T}, \mathrm{MSE}_{\text {and }} \mathrm{R}^{2}$ for individual biotransformation kinetic profiles are presented in Table 3. These were 936, 24.6 and 0.9717 for the $30 / 36 \mathrm{mM}$ initial benzaldehyde / pyruvate concentration levels and 2,526, 66.5 and 0.9787 for the $100 / 120 \mathrm{mM}$ levels, respectively.

The model validation was done on an independent biotransformation kinetic profile with initial benzaldehyde / pyruvate concentration levels of $50 / 60 \mathrm{mM}$. The relatively good quality of fitting could be observed visually as shown in Fig 1(c). $\mathrm{RSS}_{T}, \mathrm{MSE}$, and $\mathrm{R}^{2}$ of the fitted model were 662, 17.4, and 0.9863, respectively (Table 3).

Table 2: Initial searching values and optimized values of kinetic parameters with corresponding $\mathrm{RSS}_{T}, \mathrm{MSE}$, and $\mathrm{R}^{2}$ of PAC biotransformation model for partially purified PDC from C. tropicalis TISTR 5350 using initial substrates (pyruvate and benzaldehyde) concentration levels of (30/36) and (100/ 120) $\mathrm{mM}$ as well as initial volumetric enzyme activity between $1.1-1.5 \mathrm{U} \mathrm{mL}^{-1}$.

\begin{tabular}{|c|c|c|c|c|}
\hline Kinetic parameters & "Units & References & "Initial searching values & Optimized values \\
\hline$V_{P}$ & $\mathrm{mM} \min ^{-1} \%^{-1}$ & (I) & $1.55 \times 10^{-2}$ & $(6.71 \pm 0.20) \times 10^{-2}$ \\
\hline$K_{B}$ & $\mathrm{mM}^{1-h}$ & (I) & $9.00 \times 10^{-5}$ & $(1.01 \pm 0.02) \times 10^{-4}$ \\
\hline$H$ & no unit & (I) & 1.98 & $1.94 \pm 0.01$ \\
\hline$K_{m a}$ & $\mathrm{mM}$ & (I) & 4.84 & $0.70 \pm 0.01$ \\
\hline$V_{q}$ & $\min ^{-1} \%^{-1}$ & (I) & $6.38 \times 10^{-6}$ & $(1.68 \pm 0.11) \times 10^{-5}$ \\
\hline$V_{r}$ & $\min ^{-1} \mathrm{mM}^{-1} \%^{-1}$ & (I) & $9.88 \times 10^{-7}$ & $(6.06 \pm 0.37) \times 10^{-6}$ \\
\hline$k_{d l}$ & $\min ^{-1}$ & (II) & $8.89 \times 10^{-3}$ & $(5.99 \pm 0.23) \times 10^{-3}$ \\
\hline$k_{d 2}$ & $\min ^{-1} \mathrm{mM}^{-1}$ & (II) & $3.30 \times 10^{-5}$ & $(1.33 \pm<0.01) \times 10^{-5}$ \\
\hline$k_{a}$ & $\% \min ^{-1} \mathrm{mM}^{-1}$ & (II) & $1.34 \times 10^{-5}$ & $(9.38 \pm<0.01) \times 10^{-6}$ \\
\hline$t_{\text {lag }}$ & $\min$ & (II) & 1.00 & $0.42 \pm 0.37$ \\
\hline \multicolumn{3}{|c|}{$\overline{\mathbf{R S S}_{T}}$} & 67,465 & 3,462 \\
\hline \multicolumn{3}{|c|}{ MSE } & 1,775 & 91.1 \\
\hline \multicolumn{3}{|c|}{$\mathbf{R}^{2}$} & 0.7176 & 0.9772 \\
\hline
\end{tabular}

(I): Initial rate and batch biotransformation kinetics studies by Leksawasdi et al. ${ }^{18,19}$ whose values were averaged and the relevant enzyme activity unit was normalized to relative percentage; (II): Benzaldehyde deactivation kinetics with inorganic phosphate buffer activation effect by Khemacheewakul et al. ${ }^{34}$. Full name of each parameter was given in nomenclature section. 
Table 3: Apparent initial concentration values of chemical species (enzyme activity $(E)$, pyruvate $(A)$, benzaldehyde $(B)$, PAC $(P))$ in the batch biotransformation processes utilized by PAC biotransformation model with corresponding individual RSS, MSE, and $\mathrm{R}^{2}$ for partially purified PDC from $C$. tropicalis TISTR 5350. The initial volumetric enzyme activity for each experiment was between $1.1-1.5 \mathrm{U} \mathrm{mL}^{-1}$ with experimental benzaldehyde and pyruvate concentration levels of (30/36), (50/60), and (100/120) mM.

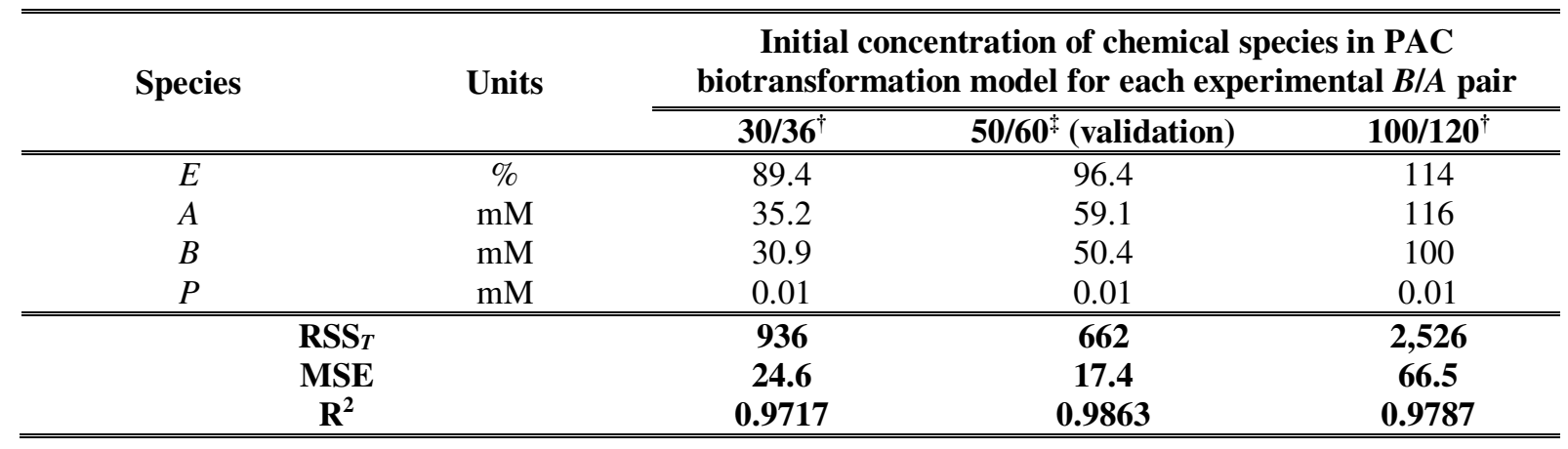

${ }^{\dagger}$ These experimental pairs were used in parameters determination process

The validity of parameters in PAC biotransformation model was confirmed by this experimental pair

Table 4: Comparison of normalized kinetic parameters from literatures and current study.

\begin{tabular}{|c|c|c|c|c|c|c|c|}
\hline $\begin{array}{c}\text { Kinetic } \\
\text { para- } \\
\text { meters } \\
\end{array}$ & \multirow{2}{*}{$\begin{array}{c}\text { Units } \\
\mathrm{mM} \mathrm{min}^{-1} \%{ }^{-1}\end{array}$} & \multicolumn{2}{|c|}{${ }^{*}$ Leksawasdi et al. ${ }^{18}$} & \multicolumn{2}{|c|}{${ }^{\dagger}$ Leksawasdi et al. ${ }^{19}$} & \multicolumn{2}{|l|}{ Current study } \\
\hline 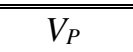 & & $(1.30 \pm 0.02) \times 10^{-2}$ & $\overline{\mathrm{c}}$ & $(1.56 \pm 0.03) \times 10^{-2}$ & $\overline{\mathrm{b}}$ & $(6.71 \pm 0.20) \times 10^{-2}$ & 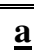 \\
\hline$K_{B}$ & $\mathrm{mM}^{1-\mathrm{h}}$ & $(1.00 \pm<0.01) \times 10^{-4}$ & $\mathbf{a}$ & $(0.80 \pm<0.01) \times 10^{-4}$ & $\mathbf{a}$ & $(1.01 \pm 0.02) \times 10^{-4}$ & $\bar{a}$ \\
\hline$h$ & no unit & $2.18 \pm 0.58$ & $\overline{\mathbf{a}}$ & $1.77 \pm 0.47$ & $\overline{\mathbf{a}}$ & $1.94 \pm 0.01$ & $\overline{\mathbf{a}}$ \\
\hline$K_{m a}$ & $\mathrm{mM}$ & $7.91 \pm 8.21^{\S}$ & $\mathbf{a , b}$ & $6.33 \pm 0.10$ & $\mathbf{a}$ & $0.70 \pm 0.01$ & $\bar{b}$ \\
\hline$V_{a}$ & $\min ^{-1} \%^{-1}$ & $(0.61 \pm<0.01) \times 10^{-5}$ & $\frac{a+0}{b}$ & $(0.03 \pm<0.01) \times 10^{-5}$ & $\frac{\mathrm{c}}{\mathrm{c}}$ & $(1.68 \pm 0.11) \times 10^{-5}$ & $\mathbf{a}$ \\
\hline$V_{r}$ & $\min ^{-1} \mathrm{mM}^{-1} \%^{-1}$ & $(0.98 \pm<0.01) \times 10^{-6}$ & $\mathrm{~b}$ & $(0.01 \pm<0.01) \times 10^{-6}$ & $\mathrm{c}$ & $(6.06 \pm 0.37) \times 10^{-6}$ & $\underline{\mathbf{a}}$ \\
\hline$k_{d l}$ & $\min ^{-1}$ & $(0.04 \pm<0.01) \times 10^{-3}$ & $\mathrm{c}$ & $(0.05 \pm<0.01) \times 10^{-3}$ & $\mathrm{~b}$ & $(5.99 \pm 0.23) \times 10^{-3}$ & $\mathbf{a}$ \\
\hline$k_{d 2}$ & $\min ^{-1} \mathrm{mM}^{-1}$ & $(0.33 \pm<0.01) \times 10^{-5}$ & $\mathrm{c}$ & $(0.40 \pm<0.01) \times 10^{-5}$ & $\mathrm{~b}$ & $(1.33 \pm<0.01) \times 10^{-5}$ & $\overline{\mathbf{a}}$ \\
\hline${ }^{\prime} k_{a}$ & $\% \min ^{-1} \mathrm{mM}^{-1}$ & $\mathrm{~N} / \mathrm{a}^{\prime}$ & & $\mathrm{N} / \mathrm{a}^{\prime \prime}$ & & $(9.38 \pm<0.01) \times 10^{-6}$ & \\
\hline$t_{\text {lag }}$ & $\min$ & $314 \pm<1$ & $\mathbf{a}$ & $252 \pm<1$ & $\mathrm{~b}$ & $0.42 \pm 0.37$ & $\mathrm{c}$ \\
\hline \multicolumn{2}{|c|}{ Prediction capability } & \multicolumn{2}{|l|}{ Interpolation } & \multicolumn{2}{|l|}{ Extrapolation } & \multicolumn{2}{|l|}{ Interpolation } \\
\hline \multicolumn{2}{|c|}{$\begin{array}{c}\text { Validated initial } \\
(B, A) \text { in } \mathrm{mM}\end{array}$} & \multicolumn{2}{|l|}{$(100,120)$} & \multicolumn{2}{|l|}{$(400,600)$} & \multicolumn{2}{|l|}{$(50,60)$} \\
\hline \multicolumn{2}{|r|}{${ }^{\pi /} \mathbf{R S S}_{T}$} & \multicolumn{2}{|l|}{1,610} & \multicolumn{2}{|l|}{11,000} & \multicolumn{2}{|l|}{662} \\
\hline \multirow{2}{*}{\multicolumn{2}{|c|}{${ }^{\mathrm{I} /}{ }_{\mathrm{I} / \mathbf{R}^{2}} \mathbf{M S E}$}} & \multicolumn{2}{|l|}{28.2} & \multicolumn{2}{|l|}{282} & \multicolumn{2}{|l|}{$\underline{\mathbf{1 7 . 4}}$} \\
\hline & & \multicolumn{2}{|l|}{$\sim 0.99$} & \multicolumn{2}{|l|}{$\sim 0.97$} & \multicolumn{2}{|l|}{$\sim 0.99$} \\
\hline
\end{tabular}

Values with different capital alphabets $(\mathrm{a}-\mathrm{c})$ in the same row indicated statistically significant difference $(p \leq 0.05)$. Statistical parameters with the highest statistically significant $(p \leq 0.05)$ or best values were bolded and underlined.

*2.5 M MOPS with $(B / A)$ of (50/60), (100/120), (150/180) mM using initial volumetric PDC activity of $1.1-3.4 \mathrm{U} \mathrm{mL}^{-1}$

${ }^{\dagger} .5 \mathrm{M}$ MOPS with $(B / A)$ of $(400 / 600) \mathrm{mM}$ using initial volumetric PDC activity of $8.4 \mathrm{U} \mathrm{mL}^{-1}$

*1 M phosphate with $(B / A)$ of (30/36), (50/60), (100/120) mM using initial volumetric PDC activity of $1.1-1.5 \mathrm{U} \mathrm{mL}^{-1}$

${ }^{\S}$ Large error of $K_{m a}$ was reported by this literature.

" $k_{a}$ was only included in current study, Khemacheewakul et al. ${ }^{34}$ reported $k_{a}$ value of $(13.4 \pm 8.6) \times 10^{-6} \% \mathrm{~min}^{-1} \mathrm{mM}^{-1}$ which was not statistical significantly different $(p>0.05)$ from current study

IIThese statistical parameters were normalized across previous studies of Leksawasdi et al. ${ }^{18,19}$ and current study so that $\mathrm{RSS}_{T}$, MSE, and $\mathrm{R}^{2}$ were comparable. 


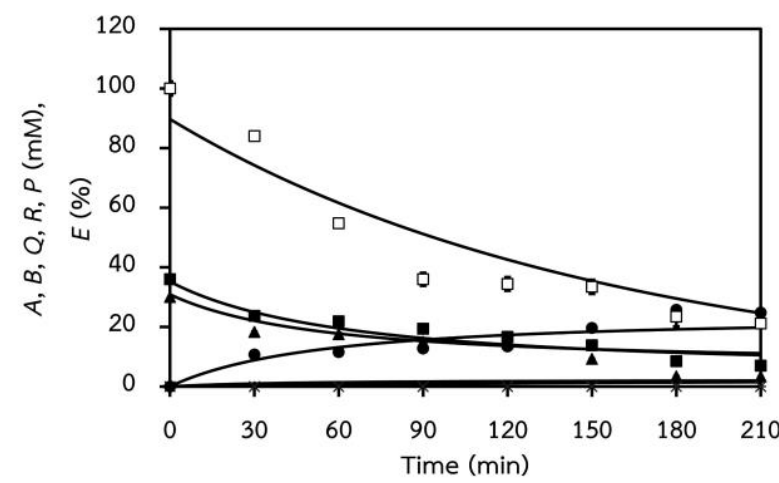

(a)

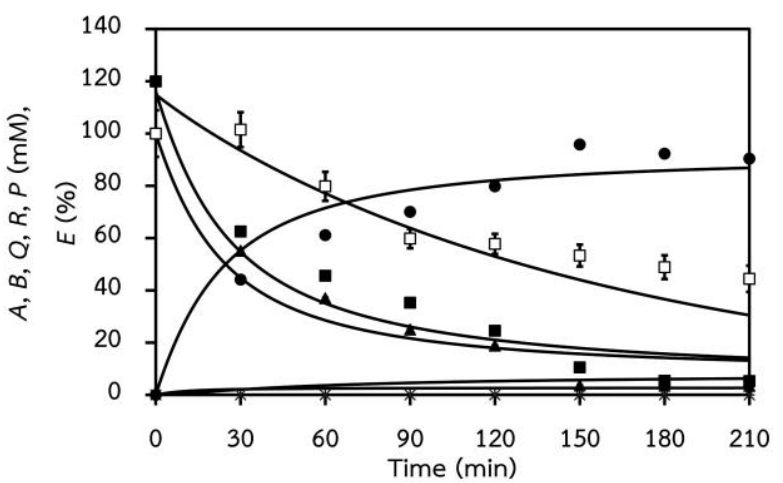

(b)

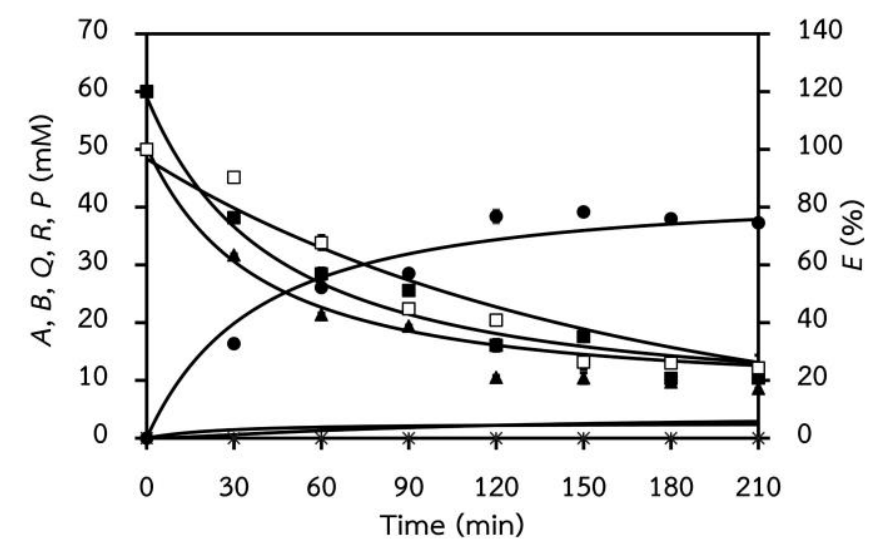

(c)

Figure 1: Simulated profiles of PAC $(P, \bullet)$ biotransformation systems with experimental initial substrates (pyruvate - $(A, \mathbf{\square})$ and benzaldehyde $(B, \mathbf{\Delta}))$ concentration levels $(\mathrm{mM})$ of $(\mathrm{a})$ : (30/36) and (b): (100/ 120) after $\operatorname{RSS}_{T}$ minimization as well as predicted profile for validation purpose with initial substrates concentration level of (c): (50/60) $\mathrm{mM}$ based on optimized parameter values as indicated in Table 2. The corresponding values of $\mathrm{RSS}_{T}$, MSE, and $\mathrm{R}^{2}$ for each profile are shown in Table 3 . The error bars had already been incorporated to all experimental data sets but were found to be relatively small for most of data sets. The initial volumetric enzyme activity $(E, \square)$ was $1.1-1.5 \mathrm{U} \mathrm{mL}^{-1}$. The formation of by-products such as acetaldehyde $(Q, \times)$ and acetoin $(R,+)$ was not detected.

\section{Discussion}

The results from the effects of phosphate buffer and initial substrates concentration levels could be compared to those reported by Khemacheewakul et al. ${ }^{34}$ when whole cells of $C$. tropicalis TISTR 5350 was used as biocatalyst instead. Whole cells biotransformation in $1 \mathrm{M}$ phosphate buffer using initial 30 / $40 \mathrm{mM}$ benzaldehyde / pyruvate substrates concentration levels could produce $P_{\max }$, equivalent $\mathrm{r}_{P \max }, \mathrm{Y}_{P / B}$, and $\mathrm{Y}_{P / A}$ of $28.6 \pm 2.3 \mathrm{mM}, 0.566 \pm 0.014 \mathrm{mM} \mathrm{min}^{-1}, 0.95$ \pm 0.08 and $0.71 \pm 0.06$, respectively. The values of $P_{\max }$ from both studies could not be directly compared due to different initial substrate concentration levels. Nevertheless, the results of $\mathrm{r}_{P \max }$ and $\mathrm{Y}_{P / A}$ were still comparable and statistically higher $(p \leq 0.05)$ by $12.9 \pm 0.3 \%$ and 23.9 $\pm 2.0 \%$, respectively for the current study which might suggest the beneficial effect of using a lower phosphate buffer concentration level $(250 \mathrm{mM})$ for PAC biotransformation system with partially purified PDC. In fact, $P_{\max }(15.5 \pm 0.1 \mathrm{mM})$ and $\mathrm{r}_{P \max }\left(0.103 \pm 0.001 \mathrm{mM} \mathrm{min}^{-1}\right)$ of partially purified $C$. tropicalis TISTR 5350 were significantly affected $(p \leq 0.05)$ by $1 \mathrm{M}$ 
phosphate buffer in comparison with the whole cells counterpart $(45.8 \pm 4.4 \%$ and $81.8 \pm 0.5 \%$ lowered, respectively) when subjected to similar initial substrates concentration level as shown in Table 1. As PDC is an intracellular enzyme, the application of this enzyme in the form of whole cells may protect the enzyme against high phosphate buffer concentrations through the mechanism of mass transfer limitation due to diffusion hindrance. However, catalytic rates may be compromised ${ }^{41}$. This was also in agreement with Rosche et al. ${ }^{32}$ who revealed that $600 \mathrm{mM}$ phosphate buffer had greater level of inhibitory effect to partially purified PDC from Rhizopus javanicus NRRL 13161 than MOPS buffer at a similar concentration level resulting in lower PAC concentration being produced. MOPS buffer was then chosen as buffer of choice for subsequent studies ${ }^{18-20,28,33}$. In fact, partially purified C. utilis PDC in 2.5 M MOPS buffer also expressed the highest $r_{P \max }$ when initial benzaldehyde / pyruvate concentration level was $100 / 120 \mathrm{mM}^{18}$. Evidently, $\mathrm{Y}_{P / B}$ was not affected by phosphate buffer concentration at $250 \mathrm{mM}$ and $1 \mathrm{M}$ as both molar yields were in the vicinity of unity and not statistically significant different $(p>0.05)$ from one another.

Several authors had discussed advantages and disadvantages of using phosphate species as reaction buffers for $\mathrm{PDC}^{2,25,32,34,42}$. Juni et al. ${ }^{42}$ pointed out that high phosphate concentration might help prevent proteolytic enzymes from deactivating PDC, thereby enhancing the PDC stability while strengthening association of important prosthetic cofactors such as TPP with the enzyme. Such protective effect from a high phosphate buffer concentration observed in this study may also be applicable to PDC from $R$. javanicus NRRL 13161, because it possesses a relatively high PAC formation rate ${ }^{32}$. . javanicus was formerly ranked as a potential candidate for the best PAC producer. However, the possibility of large-scale enzyme production from this filamentous fungal strain was eventually abandoned due to unsolvable proteolytic enzyme problems (unpublished result). Van Urk et al. ${ }^{25}$ discovered allosteric inhibition of phosphate species on $S$. cerevisiae PDC in a greater extent than that of $C$. utilis. Using phosphate buffer for PAC biotransformation with PDC from C. tropicalis TISTR 5350 may be advantageous when conducted in an optimal concentration for each enzyme form (i.e., $1 \mathrm{M}$ for whole cells $\mathrm{PDC}^{34}$ and $250 \mathrm{mM}$ for partially purified PDC (this study)). Phosphate buffer also offers costsaving advantage. Leksawasdi et al. ${ }^{17}$ proposed that utilization of phosphate buffer in a $1 \mathrm{~kg}$ PAC production system would maintain the cost ratio of reaction buffer to total production at $25.9 \%$, which is much lower than a cost ratio of $94.9 \%$ for MOPS buffer ${ }^{34}$.

Evidently, the developed PAC biotransformation model provided good fitting within the investigated range of $30 / 36$ to $100 / 120 \mathrm{mM}$ initial benzaldehyde/pyruvate concentration levels for partially purified PDC from C. tropicalis TISTR 5350. Comparison of all ten kinetic parameters determined in the current study to those with comparable normalized units in the literature is given in Table 4. $k_{a}$ was included to PAC biotransformation for the first time in current study. Khemacheewakul et al. ${ }^{34}$ reported $k_{a}$ value of $(13.4 \pm 8.6) \times 10^{-6} \% \mathrm{~min}^{-1} \mathrm{mM}^{-1}$ which was not statistical significantly different $(p>0.05)$ from current study. The inclusion of $k_{a} . P$ term in Eq. (6) allowed the effect of buffering species to be separated out from the original enzyme deactivation model which contained only $k_{d 1}, k_{d 2}$, and $t_{\text {lag }}$. The absence of $k_{a} . P$ term in previous studies would result in averaging out of buffer species activation effect to aforementioned three parameters with relatively less quality of fit as shown in Table 4. The developed mathematical model thus had potential for both interpolating and extrapolating predictive capability for relatively high buffering systems $(2.5 \mathrm{M}$ MOPS and $250 \mathrm{mM}$ 
phosphate) across two yeast strains (C. utilis and C. tropicalis) covering initial volumetric PDC carboligase activity between $1.1-8.4 \mathrm{U} \mathrm{mL}^{-1}$ and initial benzaldehyde and pyruvate concentration levels between $(30,36)$ to $(400,600) \mathrm{mM}^{18-20,34}$.

The statistical significantly highest $(p \leq 0.05)$ overall rate constant for the formation of PAC $\left(V_{p}\right)$ by using partially purified PDC from $C$. tropicalis TISTR 5350 indicated that PDC from this strain produces PAC faster than that from $C$. utilis by $4-5$ times $^{18,19}$. The improvement in value of $V_{p}$ was thus in agreement with finding in previous section where $250 \mathrm{mM}$ phosphate buffer was utilized. Further comparison was made between intrinsic binding constant $\left(K_{b}\right)$ and Hill coefficient $(h)$ for benzaldehyde whose values for both partially purified PDC from $C$. utilis and $C$. tropicalis was not statistical significantly different $(p>0.05)$ with validated range of mean between $(0.80-1.01) \times 10^{-4} \mathrm{mM}^{1-\mathrm{h}}$ and $1.77-2.18$, respectively ${ }^{18,19}$. It was possible that partially purified PDC from both strains exhibited similar allosteric and sigmoidal behaviors toward benzaldehyde. In addition, $h$ value of $\sim 2$ suggests that PDC might operate in a dimeric subunit form during PAC biotransformation ${ }^{18-20}$. The lower affinity constant value for pyruvate $\left(K_{m a}\right)$ in the current study implies a greater level of binding between partially purified PDC from $C$. tropicalis TISTR 5350 and pyruvate than the $C$. utilis counterpart by 911 times. In fact, the observably higher overall rate constants for the formation of both acetaldehyde $\left(V_{q}\right)$ and acetoin $\left(V_{r}\right)$ in the current study may be the result of increased affinity toward pyruvate of this decarboxylating enzyme ${ }^{18-20,25,31}$. Partially purified PDC from $C$. tropicalis TISTR 5350 was more prone to deactivation effect by benzaldehyde than the $C$. utilis counterpart as indicated by a much higher first-order benzaldehyde deactivation coefficient $\left(k_{d 2}\right)$ and shorter lag time for $C$. tropicalis PDC. However, the use of phosphate buffer could negate a portion this deactivating effect by providing additional activation effect. The multiplication between zeroth-order activation rate constant due to phosphate buffer $\left(k_{a}\right)$ with PDC stabilizing effect of $250 \mathrm{mM}$ phosphate buffer resulted in an activation rate of $(2.34 \pm<$ $0.02) \times 10^{-3} \% \mathrm{~min}^{-1}$. This rate was lower than the activation rates when whole cell PDC in 1 $\mathrm{M}\left(1.34 \times 10^{-2} \% \mathrm{~min}^{-1}\right)$ and $20 \mathrm{mM}\left(1.48 \times 10^{-6} \% \mathrm{~min}^{-1}\right)$ phosphate buffer were used ${ }^{34}$.

The molarity balancing of PAC formation was examined by observing PAC molar yield based on each substrate. The ranges for $\mathrm{Y}_{P / B}$ were $0.85-0.97,0.89-0.99$, and $0.93-0.99$ for the initial benzaldehyde and pyruvate concentration pairs of 30/36, 50/60, and 100/120 mM, respectively, indicating the closing molarity balance. On the contrary, corresponding ranges of of $\mathrm{Y}_{P / A}$ of $0.80-0.97,0.81-0.93$, and $0.78-0.89$ were not uniform among the tested concentration pairs. Similar phenomenon was also observed in other PAC biotransformation systems ${ }^{18-20,29,31,32,34,35}$. The formation of relatively volatile by-products such as acetaldehyde from pyruvate generally resulted in lower ranges of $Y_{P / A}$ in comparison with $Y_{P / B}$. The absence of acetaldehyde concentration in the reaction buffer and some losses in pyruvate molarity balance confirmed the volatility nature of this compound ${ }^{18-20}$. Benzyl alcohol, benzoic acid and acetoin were also not detected in the current study. Benzyl alcohol and its derivatives are often formed from side reactions of either alcohol dehydrogenase or other oxidoreductases when growing yeast cells were used in a PAC biotransformation process, resulting in a loss of up to $30-40 \%$ benzaldehyde ${ }^{26,43}$. 


\section{Conclusions}

The partially purified PDC from $C$. tropicalis TISTR 5350 with initial volumetric enzyme activity between $1.1-1.5 \mathrm{U} \mathrm{mL}^{-1}$ produced PAC at the optimized levels $(95.8 \pm 0.1 \mathrm{mM}$ and $0.639 \pm 0.001 \mathrm{mM} \mathrm{m^{-1 }}$ ) in $250 \mathrm{mM}$ phosphate buffer. The improved set of PAC biotransformation mathematical model fitted well to the kinetic biotransformation profiles of two initial concentration levels of benzaldehyde and pyruvate of 30/36 and 100/120 mM. The independent prediction of 50/60 $\mathrm{mM}$ benzaldehyde/pyruvate profile validated the interpolation ability of the developed model with corresponding $\mathrm{RSS}_{T}, \mathrm{MSE}$, and $\mathrm{R}^{2}$ of $662,17.4$, and 0.9863 , respectively. Such mathematical model will be useful for further optimization of a more complex biotransformation process, for instance, development of feeding strategies in fed batch or continuous systems.

\section{Nomenclature}

A pyruvate concentration (mM)

$B \quad$ benzaldehyde concentration (mM)

CSC convergence search criterion (no unit)

E relative enzyme activity $(\%)$

$h \quad$ Hill coefficient for benzaldehyde (no unit)

$i \quad$ iteration loop identifier for numerical integration

$k_{a} \quad$ zeroth order activation rate constant due to phosphate buffer (\% relative enzyme activity $\mathrm{min}^{-1} \mathrm{mM}^{-1}$ of phosphate buffer)

$k_{d 1} \quad$ first order reaction time deactivation constant $\left(\mathrm{min}^{-1}\right)$

$k_{d 2} \quad$ first order benzaldehyde deactivation coefficient $\left(\mathrm{mM}^{-1} \mathrm{~min}^{-1}\right)$

$K_{b} \quad$ intrinsic binding constant for benzaldehyde $\left(\mathrm{mM}^{1-\mathrm{h}}\right)$

$K_{m a} \quad$ affinity constant for pyruvate $(\mathrm{mM})$

MSE mean square error (no unit)

N/a not available

$P \quad R$-phenylacetylcarbinol concentration $(\mathrm{mM})$

PAC $R$-phenylacetylcarbinol

$P h_{b} \quad$ phosphate buffer concentration (mM)

PDC pyruvate decarboxylase enzyme

$Q \quad$ acetaldehyde concentration (mM)

$\mathrm{r}$ formation rate $\left(\mathrm{mM} \mathrm{min} \mathrm{m}^{-1}\right)$

$R \quad$ acetoin concentration $(\mathrm{mM})$

$\mathrm{R}^{2} \quad$ coefficient of determination (no unit)

RSS residual sum of squares (no unit)

$t \quad$ time (min)

$T$ total substrates and products species within the reaction buffer

$t_{\text {lag }} \quad$ lag time (min)

$\mathrm{U} \quad$ carboligase activity of PDC (unit)

$V_{p} \quad$ overall rate constant for the formation of PAC $\left(\mathrm{mM} \mathrm{min}{ }^{-1} \%^{-1}\right)$

$V_{q} \quad$ overall rate constant for the formation of acetaldehyde $\left(\mathrm{min}^{-1} \%^{-1}\right)$

$V_{r} \quad$ overall rate constant for the formation of acetoin $\left(\mathrm{min}^{-1} \mathrm{mM}^{-1} \%^{-1}\right)$

Y molar yield of $R$-phenylacetylcarbinol on each substrate (no unit) 


\section{Data Availability}

The datasets generated during and/or analysed during the current study are available from the corresponding author on reasonable request.

\section{References}

1. Smitha, M.S., S. S. \& S. R. Microbial Biotransformation: A Process for Chemical Alterations. J. Bacteriol. Mycol. Open Access 4, (2017).

2. Leksawasdi, N. et al. Longan syrup and related products: Processing technology and new product developments. in Asian Berries (ed. Xiao, G., Xu, Y. and Yu, Y.) 123148 (CRC Press, 2021).

3. Fortune Business Insights. Connected Agriculture Market Size, Share | Global Report, 2026. https://www.fortunebusinessinsights.com/connected-agriculture-market-102061.

4. Mikulic, M. Revenue of the worldwide pharmaceutical market from 2001 to 2019. https://www.statista.com/topics/1764/global-pharmaceutical-industry/ (2020).

5. Oloruntoba, A. - Revenue of the food market worldwide by country 2019 | Statista. https://www.statista.com/forecasts/758620/revenue-of-the-food-market-worldwide-bycountry (2020).

6. Seesuriyachan, P. et al. Improvement in efficiency of lignin degradation by Fenton reaction using synergistic catalytic action. Ecol. Eng. 85, 283-287 (2015).

7. Li, X. et al. Preparation and investigation of highly selective solid acid catalysts with sodium lignosulfonate for hydrolysis of hemicellulose in corncob. RSC Adv. 8, 1092210929 (2018).

8. Straathof, A. J. J., Panke, S. \& Schmid, A. The production of fine chemicals by biotransformations. Curr. Opin. Biotechnol. 13, 548-556 (2002).

9. Hegazy, M.E., Mohamed, T.A., El-Shamy, A.I., Mohamed, A.E., Mahalel, U.A., Reda, E.H., Shaheen, A.M., Tawfik, W.A., Shahat, A.A., Shams, K.A., Abdel-Azim, N.S. \& Hammouda, F. M. Microbial biotransformation as a tool for drug development based on natural products from mevalonic acid pathway: A review. J. Adv. Res. 6, 17-33 (2015).

10. Zhang, N. et al. Cell permeability and nuclear DNA staining by propidium iodide in basidiomycetous yeasts. Appl. Microbiol. Biotechnol. 102, 4183-4191 (2018).

11. Takenaka, S. et al. Characterization of the native form and the carboxy-terminally truncated halotolerant form of $\alpha$-amylases from Bacillus subtilis strain FP-133. $J$. Basic Microbiol. 55, 780-789 (2015).

12. Leksawasdi, N., Joachimsthal, E. L. \& Rogers, P. L. Mathematical modelling of ethanol production from glucose/xylose mixtures by recombinant Zymomonas mobilis. Biotechnol. Lett. 23, 1087-1093 (2001).

13. Prommajak, T., Leksawasdi, N. \& Rattanapanone, N. Biotechnological valorization of cashew apple: A review. Chiang Mai Univ. J. Nat. Sci. 13, 159-182 (2014).

14. Yuvadetkun, P., Leksawasdi, N. \& Boonmee, M. Kinetic modeling of Candida shehatae ATCC 22984 on xylose and glucose for ethanol production. Prep. Biochem. 
Biotechnol. 47, 268-275 (2017).

15. Nunta, R., Techapun, C., Kuntiya, A., Hanmoungjai, P., Moukamnerd, C.,

Khemacheewakul, J., Somma-nee, S., Reungsang, A., Kongkeitkajorn, M.B. \& Leksawasdi, N. Batch and continuous cultivation processes of Candida tropicalis TISTR 5306 for ethanol and pyruvate decarboxylase production in fresh longan juice with optimal carbon to nitrogen molar ratio. J. Food Process Eng. 42, e13227 (2019).

16. Wattanapanom, S., Muenseema, J., Techapun, C., Jantanasakulwong, K., Sanguanchaipai-wong, V., Chaiyaso, T., Hanmoungjai, P., Seesuriyachan, P., Khemacheewakul, J., Nunta, R., Sommanee, S., Mahakuntha, C., Maniyom, S., Jinsiriwanit, S., Moukamnerd, C., and, N. Kinetic Parameters of Candida tropicalis TISTR 5306 for Ethanol Production Process Using an Optimal Enzymatic Digestion Strategy of Assorted Grade Longan Solid Waste Powder. Chiang Mai J. Sci. 46, 1-19 (2019).

17. Mahakuntha, C., Reungsang, A., Nunta, R. \& Leksawasdi, N. Kinetics of whole cells and ethanol production from Candida tropicalis TISTR 5306 Cultivation in batch and fed-batch modes using assorted grade fresh longan juice. An. Acad. Bras. Cienc. (2021).

18. Leksawasdi, N. et al. Kinetic analysis and modelling of enzymatic (R)phenylacetylcarbinol batch biotransformation process. J. Biotechnol. 111, 179-189 (2004).

19. Leksawasdi, N., Rosche, B. \& Rogers, P. L. Mathematical model for kinetics of enzymatic conversion of benzaldehyde and pyruvate to (R)-phenylacetylcarbinol. Biochem. Eng. J. 23, 211-220 (2005).

20. Leksawasdi, N., Rogers, P. L. \& Rosche, B. Improved enzymatic two-phase biotransformation for ( $R$ )-phenylacetylcarbinol: Effect of dipropylene glycol and modes of pH control. Biocatal. Biotransformation 23, 445-451 (2005).

21. Tangtua, J., Techapun, C., Pratanaphon, R., Kuntiya, A., Chaiyaso, T., Hanmuongjai, P., Seesuriyachan, P. \& Leksawasdi, N. Screening of 50 Microbial Strains for Production of Ethanol and (R)-phenylacetylcarbinol. Chiang Mai J. Sci 40, 299-304 (2013).

22. Tangtua, J., Techapun, C., Pratanaphon, R., Kuntiya, A., Chaiyaso, T., Hanmuangjai, P., Seesuriyachan, P., Sanguanchaipaiwong, V., Leksawasdi, N. \& Leksawasdi, N. Evaluation of cells disruption for partial isolation of intracellular pyruvate decarboxylase enzyme by silver nanoparticles method. Acta Aliment. 44, 436-442 (2015).

23. Tangtua, J., Techapun, C., Pratanaphon, R., Kuntiya, A., Chaiyaso, T., Hanmoungjai, P., Seesuriyachan, P., Sanguanchaipaiwong, V., Leksawasdi, N. \& Leksawasdi, N. Partial Purification and Comparison of Precipitation Techniques of Pyruvate Decarboxylase Enzyme. Chiang Mai J. Sci. 44, 184-192 (2017).

24. Nunta, R. et al. Ethanol and phenylacetylcarbinol production processes of Candida tropicalis TISTR 5306 and Saccharomyces cerevisiae TISTR 5606 in fresh juices from longan fruit of various sizes. J. Food Process. Preserv. 42, e13815 (2018).

25. van Urk, H. et al. Localization and kinetics of pyruvate-metabolizing enzymes in relation to aerobic alcoholic fermentation in Saccharomyces cerevisiae CBS 8066 and 
Candida utilis CBS 621. BBA - Gen. Subj. 992, 78-86 (1989).

26. Rogers, P.L., Shin, H.S. \& Wang, B. Biotransformation for L-ephedrine production. Adv. Biochem. Eng. Biotechnol. 56, 33-59 (1997).

27. Ward, O. P. \& Singh, A. Enzymatic asymmetric synthesis by decarboxylases. Curr. Opin. Biotechnol. 11, 520-526 (2000).

28. Leksawasdi, N., Breuer, M., Hauer, B., Rosche, B. \& Rogers, P. L. Kinetics of pyruvate decarboxylase deactivation by benzaldehyde. Biocatal. Biotransformation 21, 315-320 (2003).

29. Rosche, B., Sandford, V., Breuer, M., Hauer, B. \& Rogers, P. Biotransformation of benzaldehyde into (R)-phenylacetylcarbinol by filamentous fungi or their extracts. Appl. Microbiol. Biotechnol. 57, 309-315 (2001).

30. Iranmanesh, E., Asadollahi, M. A. \& Biria, D. Improving L-phenylacetylcarbinol production in Saccharomyces cerevisiae by in silico aided metabolic engineering. $J$. Biotechnol. 308, 27-34 (2020).

31. Shin, H. S. \& Rogers, P. L. Production of L-phenylacetylcarbinol (L-PAC) from benzaldehyde using partially purified pyruvate decarboxylase (PDC). Biotechnol. Bioeng. 49, 52-62 (1996).

32. Rosche, B. et al. Enzymatic (R)-phenylacetylcarbinol production in benzaldehyde emulsions. Appl. Microbiol. Biotechnol. 60, 94-100 (2002).

33. Leksawasdi, N., Rosche, B. \& Rogers, P. Enzymatic processes for fine chemicals and pharmaceuticals: Kinetic simulation for optimal R-phenylacetylcarbinol production. in Studies in Surface Science and Catalysis, New Developments and Application in Chemical Reaction Engineering 27-34 (Elsevier Inc., 2006).

34. Khemacheewakul, J., Techapun, C., Kuntiya, A., Sanguanchaipaiwong, V., Chaiyaso, T., Hanmoungjai, P., Seesuriyachan, P., Leksawasdi, N., Nunta, R., Sommanee, S., Jantanasakulwong, K., Chakrabanhdu, Y. \& Leksawasdi, N. Development of Mathematical Model for Pyruvate Decarboxylase Deactivation Kinetics by Benzaldehyde with Inorganic Phosphate Activation Effect. Chiang Mai J. Sci 45, 1426-1438 (2018).

35. Rosche, B., Sandford, V., Breuer, M., Hauer, B. \& Rogers, P. L. Enhanced production of R-phenylacetylcarbinol (R-PAC) through enzymatic biotransformation. J. Mol. Catal. B Enzym. 19, 109-115 (2002).

36. Gomori, G. [16] Preparation of buffers for use in enzyme studies. Methods Enzymol. 1, 138-146 (1955).

37. Zeppa, G., Conterno, L. \& Gerbi, V. Determination of organic acids, sugars, diacetyl, and acetoin in cheese by high-performance liquid chromatography. J. Agric. Food Chem. 49, 2722-2726 (2001).

38. Czok, R. \& Lamprecht, W. Pyruvate, phosphoenolpyruvate and D-glycerate-2phosphate. in Methods of Enzymatic Analysis (ed. Bergmeyer, H. U.) 403-410 (1974).

39. Bernt, E. \& Bergmeyer, H. U. Acetaldehyde: determination with alcohol dehydrogenase from yeast. in Methods of Enzymatic Analysis (ed. Hans-UIrich Bergmeyer) 1696-1700 (Academic Press, 1965). 
40. Skoog, D. A., West, D. M., Holler, F. J., Crouch, S. R., \& Cengage, R. C. Skoog and West's fundamentals of analytical chemistry (9th ed.). (Andover, England: Cengage Learning, 2014).

41. Ladkau, N., Hermann, I., Bühler, B. \& Schmid, A. Enzyme-Catalyzed Laurolactam Synthesis via Intramolecular Amide Bond Formation in Aqueous Solution. Adv. Synth. Catal. 353, 2501-2510 (2011).

42. Juni, E. \& Heym, G. A. Properties of yeast pyruvate decarboxylase and their modification by proteolytic enzymes. I. Stability of decarboxylases from wild-type and mutant strains. Arch. Biochem. Biophys. 127, 79-88 (1968).

43. Kunjapur, A. M. \& Prather, K. L. J. Microbial engineering for aldehyde synthesis. Appl. Environ. Microbiol. 81, 1892-1901 (2015).

\section{Acknowledgements}

This project is funded by National Research Council of Thailand (NRCT) (Grant Number: NRCT5-RSA63004-08), TRF Senior Research Scholar (Grant Number: RTA6280001), Chiang Mai University (CMU), and Bioprocess Research Cluster (BRC), Faculty of AgroIndustry, CMU. Thailand Institute of Scientific and Technological Research (TISTR) is also thanked for microbial strain support.

\section{Competing interests}

The authors report no conflicts of interest. The authors alone are responsible for the content and writing of the paper.

\section{Author contributions}

J.K. and N.L. designed the study. J.K. performed the experiments, collected, and analyzed the data. N.L. and Y.P. checked the validity of model. J.K., N.L., K.P., S.S., and C.M. performed statistical analyses. J.K. and N.L. wrote the initial draft of the manuscript. S.T., R.N., C.T., Y.P., P.R., K.J., K.P., S.S., C.M., T.C., P.S., A.R., N.T.N.T., S.W., S.R.S. revised the manuscript. J.K. and N.L. wrote the final version of the manuscript. All authors reviewed the final version of the manuscript. 
Figures

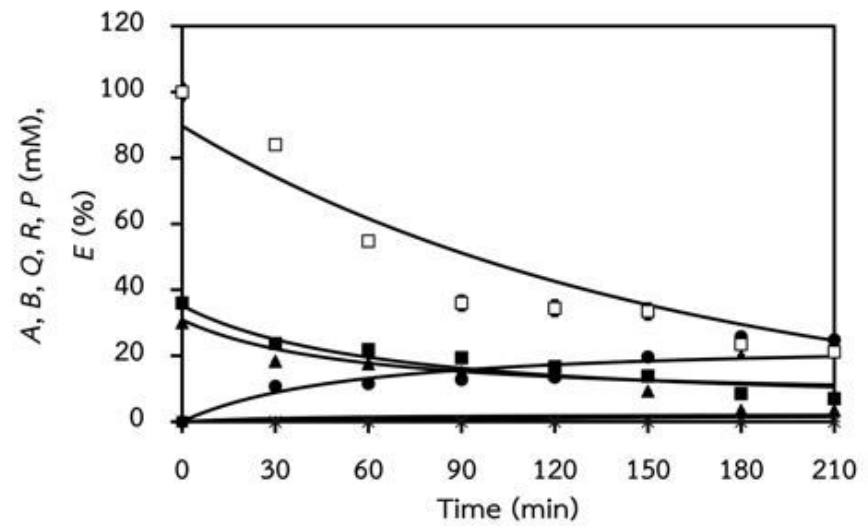

(a)

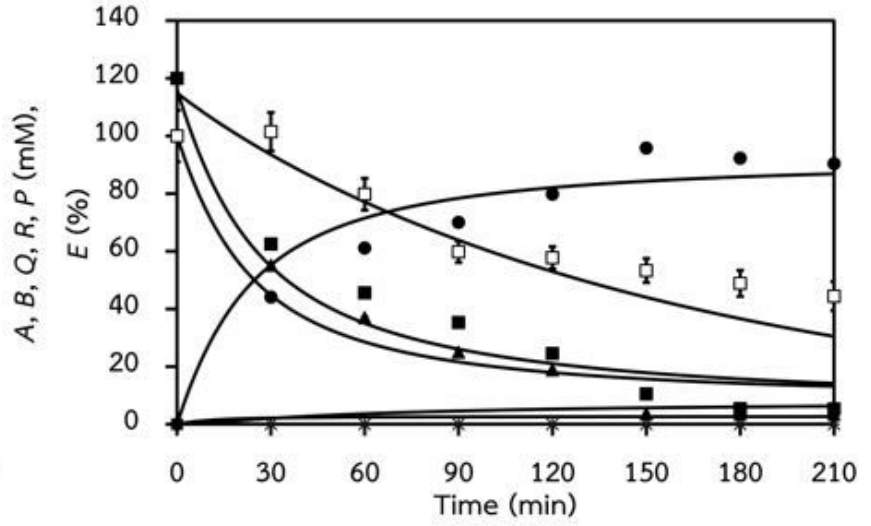

(b)

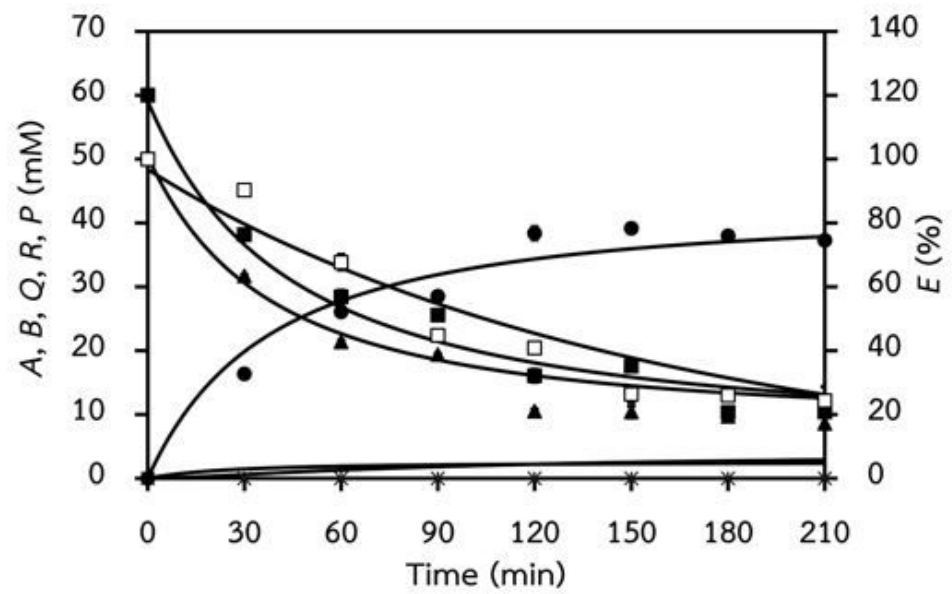

(c)

Figure 1

please see the manuscript file for the full caption 